\title{
Plasma contact factors as novel biomarkers for diagnosing Alzheimer's disease
}

Jung Eun Park', Do Sung Lim, ${ }^{1,2}$, Yeong Hee Cho ${ }^{1,2}$, Kyu Yeong Choi ${ }^{3}$, Jang Jae Lee ${ }^{3}$, Byeong C. Kim4, Kun Ho Lee ${ }^{1,3}$ and Jung Sup Lee ${\text { L, } 1,3^{*}}^{1}$

\begin{abstract}
Background: Alzheimer's disease (AD) is the most common cause of dementia and most of AD patients suffer from vascular abnormalities and neuroinflammation. There is an urgent need to develop novel blood biomarkers capable of diagnosing Alzheimer's disease (AD) at very early stage. This study was performed to find out new accurate plasma diagnostic biomarkers for AD by investigating a direct relationship between plasma contact system and AD.

Methods: A total 101 of human CSF and plasma samples from normal and AD patients were analyzed. The contact factor activities in plasma were measured with the corresponding specific peptide substrates.

Results: The activities of contact factors (FXIla, FXla, plasma kallikrein) and FXa clearly increased and statistically correlated as AD progresses. We present here, for the first time, the FXIla cut-off scores to as: $>26.3 \mathrm{U} / \mathrm{ml}$ for prodromal $\mathrm{AD}$ [area under the curve $(\mathrm{AUC})=0.783, p<0.001$ ] and $>27.2 \mathrm{U} / \mathrm{ml}$ for $\mathrm{AD}$ dementia ( $\mathrm{AUC}=0.906, p<0.001$ ). We also describe the cut-off scores from the ratios of CSF $A \beta_{1-42}$ versus the contact factors. Of these, the representative ratio cut-off scores of $A \beta_{1-42} / F X l l a$ were to be: $<33.8$ for prodromal $A D$ ( $A U C=0.965, p<0.001$ ) and $<27.44$ for $A D$ dementia ( $A \cup C=1.0, p<0.001$ ).

Conclusion: The activation of plasma contact system is closely associated with clinical stage of AD, and FXIla activity as well as the cut-off scores of CSF A $\beta_{1-42} / F X I l a$ can be used as novel accurate diagnostic AD biomarkers.
\end{abstract}

Keywords: Alzheimer's disease, Biomarkers, Contact factor, FXlla, Plasma

\section{Background}

Alzheimer's disease (AD) is the most common cause of dementia, accounting for $60-80 \%$ of all dementia patients. However, the cause of $\mathrm{AD}$ is poorly understood and there are no treatments currently available. To date, the only way to take care of $\mathrm{AD}$ is to find out in advance the onset and prevent the progression $[1,2]$. Over the past decades, there have been many efforts to develop blood biomarkers

\footnotetext{
* Correspondence: jsplee@chosun.ac.kr

${ }^{1}$ Department of Biomedical Science, College of Natural Sciences, Chosun University, 309 Pilmun-Daero, Gwangju 61452, Republic of Korea ${ }^{2}$ Department of Integrative Biological Sciences \& BK21-Four Educational Research Group for Age-associated Disorder Control Technology, Chosun University, Gwangju, Republic of Korea

Full list of author information is available at the end of the article
}

that can easily and reliably detect the onset of Alzheimer's, but it has been delayed due to the lack of reproducibility and other problems related to clinical use [3, 4]. Nevertheless, the identification of novel blood biomarkers for predicting and monitoring disease progression that can reliably detect the onset of $\mathrm{AD}$ at the early stage is crucial.

$\mathrm{AD}$ is a neurodegenerative disease characterized by amyloid-beta $(A \beta)$ deposits in brain [5-7], and most of AD patients suffer from vascular abnormalities $[8,9]$ and neuroinflammation [10]. Both vascular abnormalities and inflammation can trigger neuronal death; however, the effect of $A \beta$ on these pathologies has not been elucidated. However, a few recent reports have suggested that FXII-initiated contact system can trigger both

C C The Author(s). 2021 Open Access This article is licensed under a Creative Commons Attribution 4.0 International License, which permits use, sharing, adaptation, distribution and reproduction in any medium or format, as long as you give appropriate credit to the original author(s) and the source, provide a link to the Creative Commons licence, and indicate if changes were made. The images or other third party material in this article are included in the article's Creative Commons licence, unless indicated otherwise in a credit line to the material. If material is not included in the article's Creative Commons licence and your intended use is not permitted by statutory regulation or exceeds the permitted use, you will need to obtain permission directly from the copyright holder. To view a copy of this licence, visit http://creativecommons.org/licenses/by/4.0/ The Creative Commons Public Domain Dedication waiver (http://creativecommons.org/publicdomain/zero/1.0/) applies to the data made available in this article, unless otherwise stated in a credit line to the data. 
vascular pathology and inflammation [11], and depletion of coagulation FXII can ameliorate brain pathology and cognitive impairment in AD mice [12].

The plasma contact system, which is composed of the intrinsic pathway of coagulation and the kallikrein-kinin system, plays an essential role in innate immunity [1315]. Activation of the plasma contact system triggers several cascade systems that involve three serine protease zymogens [factor XII (FXII), factor XI (FXI), and prekallikrein (PKK)] and a non-enzymatic cofactor protein [high-molecular weight kininogen (HK)] [13]. The enzymatically active FXIIa activates PKK to plasma kallikrein (PK; KLKB1) that cleaves HK to release the vasoactive and proinflammatory nanopeptide, bradykinin (BK).

Several recent studies have shown a possible relationship between plasma contact system and AD. However, they did not provide any solid evidence, because of their uses of data from a very few human CSF samples or murine models [11, 12, 15-19]. Accordingly, there are still a variety of issues related to contact system and $\mathrm{AD}$, including 1) Is there a close correlation between contact system and $\mathrm{AD}$ progression in fact?; and 2) Is it possible to obtain various cut-off scores and certain ratios for distinguishing accurately prodromal $\mathrm{AD}$ and $\mathrm{AD}$ dementia from normal subjects?

In this study, we addressed these issues and present, for the first time, the direct relationship between the contact system activation and AD progress, and the cutoff scores of FXIIa and CSF $A \beta_{1-42} /$ FXIIa ratio, which are capable of discriminating accurately prodromal $\mathrm{AD}$ and $\mathrm{AD}$ dementia from normal subjects.

\section{Methods}

\section{Study participants}

This study was conducted on participants in Gwangju and Jeollanam-do, Republic of Korea, from August 2015 to October 2017. All participants in this study provided their written consents, and the study protocol was approved by Chosun University Hospital Institutional Review Board (IRB file numbers 2013-12-018-068 and 2016-10-005-009). A total of 101 subjects included in the study were classified into three groups (50 normal elderly people, 23 patients with prodromal $\mathrm{AD}$, and 28 patients with $\mathrm{AD}$ dementia) according to the clinical criteria proposed by the IWG-2 guidelines with amyloid PET [16]. However, PET positive group in normal subjects (preclinical stage of $\mathrm{AD}$ ) and amyloid PET negative group in mild cognitive impairment (MCI) were excluded. Patients with AD dementia met the clinical criteria for Alzheimer's disease dementia potential proposed by the NIA-AA or IWG-2 working group, and the diagnosis of $\mathrm{MCI}$ was also made according to the MCI criteria suggested by the NIA-AA or IWG-2 group $[20,21]$.
Determination of the concentrations of $A \beta_{1-42}, t-T a u, p-$ $\mathrm{Tau}_{181}$, and bradykinin

The collection and storage of CSF used in this study was performed in the same process as follows [22]. The concentrations of $\mathrm{A} \beta_{1-42}, \mathrm{t}-\mathrm{Tau}$, and $\mathrm{p}-\mathrm{Tau}_{181}$ in CSF were measured using INNOTEST ELISA kit (Fujirebio, Ghent, Belgium) and that of bradykinin (BK) was quantitated with Bradykinin ELISA kit (Enzo Life Sciences, Farmingdale, NY, USA) according to the protocols provided by the manufacturers.

\section{Measurement of the activities of FXIla, FXIa, FXa, and PK in plasma}

Plasma used in this study was collected and stored from participants according to the Molecular Medicine Ireland (MMI) guidelines for standardized biobanking [23]. To measure and make the standard curves for FXIIa, FXIa, FXa, and PK activities, various concentrations of FXIIa $(0,0.5,1,1.5,2,2.5$, and $4 \mathrm{U} / \mathrm{ml})$, FXIa $(0$, $0.01,0.02,0.05,0.1,0.2$, and $0.4 \mathrm{U} / \mathrm{ml})$, FXa $(0,0.01$, $0.05,0.1,0.2,0.5$, and $1 \mathrm{U} / \mathrm{ml})$, and PK $(0,0.02,0.04$, $0.08,0.1,0.2$, and $0.4 \mathrm{U} / \mathrm{ml}$ ) were serially diluted in phosphate buffered saline (PBS, pH 7.5). After the dilutions, $90 \mu \mathrm{l}$ each of samples was mixed with $10 \mu \mathrm{l}$ of corresponding synthetic peptide substrates (S-2302 for FXIIa, S-2366 for FXIa, S-2765 for FXa, and H-D-Val-Leu-ArgAFC for kallikrein) dissolved in PBS ( $\mathrm{pH} 7.5)$ at a final concentration of $4 \mathrm{mM}$ and incubated for $30 \mathrm{~min}$ at $37^{\circ} \mathrm{C}$, during which the increase in absorbance at 405 $\mathrm{nm}$ for chromogenic substrates or in fluorescence for fluorogenic substrate (excitation $400 \mathrm{~nm} /$ emission 505 $\mathrm{nm}$ ) was recorded with a 96-well plate reader (Molecular Devices, San Jose, CA, USA) as described previously [13]. All experiments were performed in triplicate. Using the data obtained, standard curves for the enzymes were then made using a sigmoidal 4 parameter curve fitting (Supplementary Fig. 1). To validate the measurement method, total 6 plasma samples and 3 different concentrations of contact factors (FXIIa, FXIa, and PK) and FXa were tested over different days.

\section{Statistical analysis}

Statistical analysis was performed with SPSS version 24.0 (IBM Corp., Armonk, NY, USA), and analysis of variance (ANOVA) was used to compare the three groups (normal, prodromal AD, and AD dementia). Pearson's correlation analysis was used to analyze the association between the activity of plasma contact system and the typical CSF AD biomarkers. Receiver operator characteristic (ROC) curves were generated to calculate areas under the curves (AUCs) to determine the diagnostic abilities of the contact factors and the typical CSF AD biomarkers for prodromal $\mathrm{AD}$ and $\mathrm{AD}$ dementia. The standard deviations from the mean value of the 
quantitative analysis or activity of each protein in the cohort used in this study was calculated as the $z$-score.

\section{Results and discussion}

\section{Concentration of CSF biomarkers in AD}

The clinical characteristics of total 101 subjects (50 normal subjects, 23 patients with prodromal AD, and 28 patients with $\mathrm{AD}$ dementia) and the concentrations of typical AD biomarkers, including $A \beta_{1-42}, t-T a u$, and $p-$ $\mathrm{Tau}_{181}$ in CSF and contact factors (FXIIa, FXIa, PK, and $\mathrm{BK})$ and FXa in plasma samples are summarized in Table 1 . As reported previously $[2,5,24,25], A \beta_{1-42}$ level in CSF decreased, while t-Tau and p-Tau181 concentrations increased with AD progression (Figs. 1a, c). The concentrations of CSF $A \beta_{1-42}$ were estimated to be 1059,550 and $484 \mathrm{pg} / \mathrm{ml}$ in normal, prodromal AD, and AD dementia groups, respectively (Table 1). Contrary to these, the levels of $\mathrm{t}-\mathrm{Tau}$ and $\mathrm{p}-\mathrm{Tau}_{181}$ increased as AD progressed, in which the concentrations of t-Tau were found to be 230,389 , and $536 \mathrm{pg} / \mathrm{ml}$, and those of p$\mathrm{Tau}_{181}$ were 44, 66, and $78 \mathrm{pg} / \mathrm{ml}$ in normal, prodromal $\mathrm{AD}$, and $\mathrm{AD}$ dementia groups, respectively (Table 1 ).
These results were well in accordance with reported previous studies [2, 24, 25].

\section{Activation of contact system in AD}

To measure the activation of the contact system in plasma, the assay validation standard curves were created using the recombinant contact factor (FXIIa, FXIa, and PK) and FXa enzymes. As a result, the $R^{2}$ values of standard curves were higher than 0.95 (Supplementary Fig. 1). In addition, the coefficients of variation (CV\%) were analyzed to confirm the precision and reproducibility of the measurement method for contact factor activity. As a result, the inter-assay and intra-assay CVs (\%) ranged for FXIIa from 3.2 to $4.5 \%$ and from 7.2 to $12.7 \%$, which indicated the excellent reproducibility of this method (Table 2).

The enzymatic activities of the plasma contact factors (FXIIa, FXIa, and PK) and FXa clearly increased with AD progression. The enzymatic activities for the normal, prodromal $\mathrm{AD}$, and $\mathrm{AD}$ dementia groups were as follows: 23.9, 28.0, and 30.6 U/ml for FXIIa; 1.11, 1.18, and $1.30 \mathrm{U} / \mathrm{ml}$ for FXIa; 0.77, 0.81, and $0.97 \mathrm{U} / \mathrm{ml}$ for FXa; $1.20,1.35$, and $1.54 \mathrm{U} / \mathrm{ml}$ for $\mathrm{PK}$, respectively (Table 1 ).

Table 1 Demographic and biochemical characteristics of normal subjects, prodromal AD, and AD dementia

\begin{tabular}{|c|c|c|c|c|c|}
\hline Demographic data/molecules in CSF or plasma & Total numbers of subjects & Normal & Prodromal AD & AD dementia & $p$ value \\
\hline Number of subjects & 101 & 50 & 23 & 28 & \\
\hline Age & 101 & $72.0(6.1)$ & $71.1(8.6)$ & $69.4(6.0)$ & 0.262 \\
\hline Years of education & 101 & $9.5(5.0)$ & $8.0(4.7)$ & $6.70(3.8)^{\mathrm{a}}$ & 0.033 \\
\hline Gender, female, n (\%) & 101 & $26.0(52.0)$ & $12(52.2)$ & $17.0(60.7)$ & 0.736 \\
\hline K-MMSE score & 101 & $26.8(2.3)$ & $25.3(3.9)$ & $17.9(5.4)^{a, b}$ & $<0.001$ \\
\hline $\mathrm{CDR}$ & 101 & $0.3(0.2)$ & $0.5(0.0)^{a}$ & $0.9(0.4)^{a, b}$ & $<0.001$ \\
\hline CDR sum of boxes & 101 & $0.5(0.6)$ & $1.3(0.6)$ & $5.1(2.6)^{a, b}$ & $<0.001$ \\
\hline GDS & 101 & $1.6(0.5)$ & $3.0(0.2)^{a}$ & $4.1(0.9)^{\mathrm{a}, \mathrm{b}}$ & $<0.001$ \\
\hline B-ADL & 101 & $20.0(0.0)$ & $20.0(0.2)$ & $19.0(1.8)^{a, b}$ & $<0.001$ \\
\hline I-ADL & 101 & $0.04(0.08)$ & $0.22(0.14)^{a}$ & $0.63(0.20)^{a, b}$ & $<0.001$ \\
\hline \multicolumn{6}{|l|}{ CSF biomarkers } \\
\hline $\mathrm{A} \beta_{1-42}, \mathrm{pg} / \mathrm{ml}$ & 101 & $1,059(177)$ & $550(223)^{a}$ & $484(192)^{a}$ & $<0.001$ \\
\hline $\mathrm{t}-\mathrm{Tau}, \mathrm{pg} / \mathrm{ml}$ & 101 & $230(77)$ & $389(236)^{a}$ & $536(209)^{a, b}$ & $<0.001$ \\
\hline $\mathrm{p}-\mathrm{Tau}_{181}, \mathrm{pg} / \mathrm{ml}$ & 101 & $44(14)$ & $66(33)^{a}$ & $78(28)^{a}$ & $<0.001$ \\
\hline $\mathrm{BK}, \mathrm{pg} / \mathrm{ml}$ & 72 & $83(49)$ & $55(45)$ & $39(33)^{a}$ & 0.002 \\
\hline \multicolumn{6}{|l|}{ Plasma factors } \\
\hline FXIla, U/ml & 101 & $23.90(3.70)$ & $28.0(3.4)^{\mathrm{a}}$ & $30.6(3.7)^{a}$ & $<0.001$ \\
\hline FXla, U/ml & 101 & $1.11(0.21)$ & $1.18(0.21)$ & $1.30(0.30)^{a}$ & 0.005 \\
\hline $\mathrm{FXa}, \mathrm{U} / \mathrm{ml}$ & 101 & $0.77(0.11)$ & $0.81(0.12)$ & $0.97(0.29)^{a, b}$ & $<0.001$ \\
\hline Kallikrein, U/ml & 101 & $1.20(0.25)$ & $1.35(0.34)$ & $1.54(0.39)^{a}$ & $<0.001$ \\
\hline $\mathrm{BK}, \mathrm{pg} / \mathrm{ml}$ & 90 & $13,365(9,305)$ & $13,497(7,945)$ & $17,679(21,186)$ & 0.406 \\
\hline
\end{tabular}

Data are presented as mean ( \pm standard deviation) or number (\%). Abbreviations: K-MMSE Korean Mini-Mental State Examination, CDR Clinical Dementia Rating, GDS Global Deterioration Scale, $B$-ADL Barthel Activities of Daily Living, I-ADL Instrumental Activities of Daily Living, CSF cerebrospinal fluid, $A \beta$ amyloid betaprotein, $t$-Tau total Tau protein, $p$-Tau phosphorylated Tau protein, $A D$ Alzheimer's disease, $B K$ bradykinin. ${ }^{a}$ statistically significant difference between the indicated group and the normal group; ${ }^{b}$ statically significant difference between prodromal $A D$ and $A D$ dementia groups 

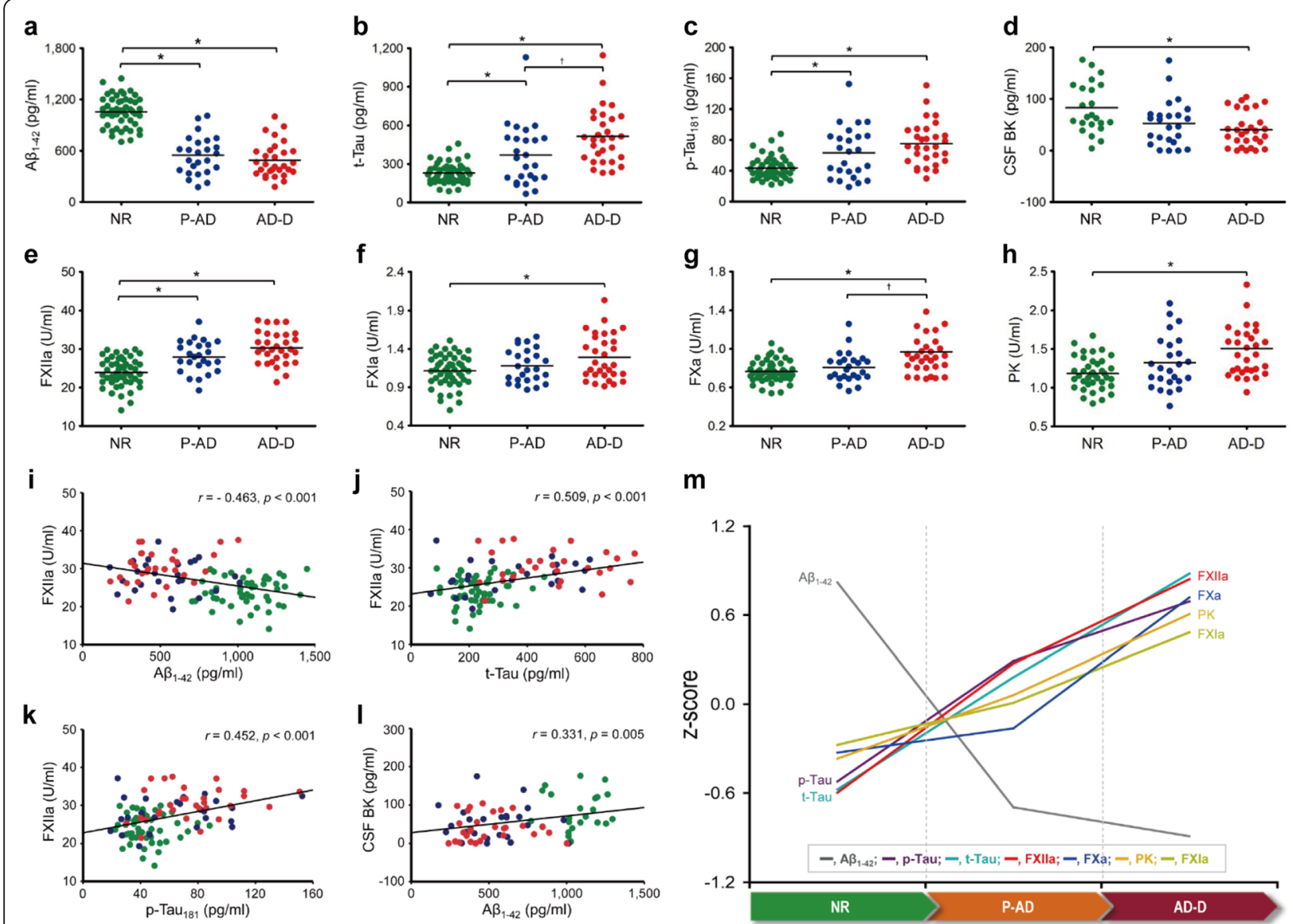

m

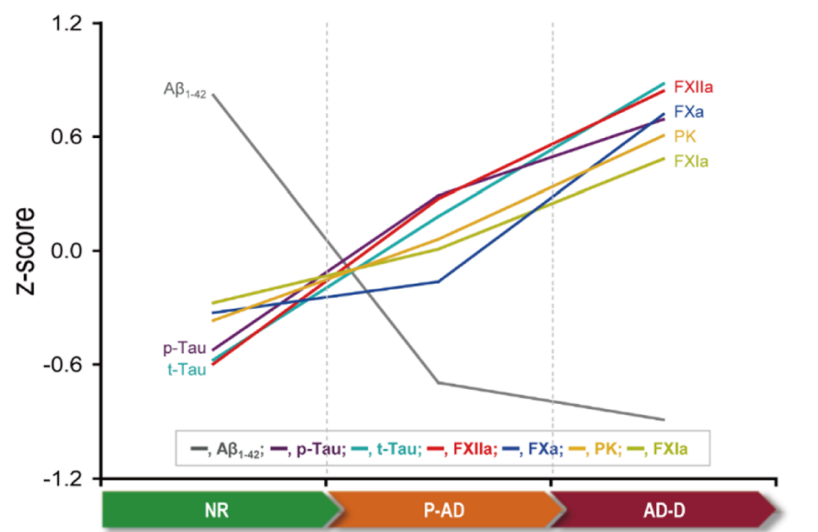

Fig. 1 Activation of plasma contact factors with clinical stage of $A D$ and correlation strengths between biomarkers. Concentrations of typical $A D$ biomarkers, including $A \beta_{1-42}(\mathbf{a}), \mathrm{t}-\mathrm{Tau}(\mathbf{b}), \mathrm{p}-\mathrm{Tau}_{181}(\mathbf{c})$ and BK (d) in CSF were measured from normal (NR), prodromal AD (P-AD), and AD dementia (AD-D) groups by ELISA. The activities of plasma contact factors such as FXlla (e), FXla (f), FXa (g), and kallikrein (h) were measured in the presence of $0.4 \mathrm{mM}$ each of corresponding specific synthetic peptide substrates as described in Study design. Statistical analysis was performed using SPSS version 24.0 (IBM Corp., Armonk, NY, USA), and analysis of variance (ANOVA) was performed for comparisons between the three groups (NR, P-AD, and AD-D). Data are presented as mean values for each group. *: statistically significant difference between the indicated group and the NR; ${ }^{\dagger}$ : statistically significant difference between the P-AD and the AD-D groups. Correlation plots of FXIla versus A $\beta_{1-42}$ (i), FXIla versus t-Tau (j), FXIla versus p-Tau 181 (k), and CSF BK versus $A \beta_{1-42}$ (I). Pearson's correlation analysis was used to analyze the correlations between the activity of plasma contact factor and CSF AD biomarker as indicated, in which statistical significance was set at $p<0.05$. In panels a to I, cyan, blue, and red colored circles represent NR, P-AD, and AD-D groups, respectively. Dynamics of biomarkers analyzed in AD pathological cascade (m). Lines show $z$-scores in mean values of normalized biomarker levels for each AD group

Taken as a whole, the activities of contact factors (FXIIa, FXIa, or PK) and FXa had a statically difference between the three groups (normal, prodromal $\mathrm{AD}$, and $\mathrm{AD}$ dementia groups) (Fig. 1e, h). As for BK, which is a final product of the kallikrein/kinin system [26], its concentration increased in plasma as expected, but rather decreased in CSF with the progression of AD (Table 1; Fig. 1d). The concentrations of BK in plasma were 13,365 , 13,497 , and $17,679 \mathrm{pg} / \mathrm{ml}$ and those in CSF were 83,55 , and $39 \mathrm{pg} / \mathrm{ml}$ in normal, prodromal $\mathrm{AD}$, and AD dementia groups, respectively. These results are consistent with the those of recent reports [27] and also seemed to be related, in part, to the fact that BK can evoke bloodbrain barrier (BBB) leakage and neuro-inflammation, resulting in CSF BK efflux $[15,28]$. All these results suggest that the activation of plasma contact system and $\mathrm{AD}$ progression are obviously related, and the activities of contact factors can be used for discriminating prodromal $\mathrm{AD}$ and $\mathrm{AD}$ from normal groups.

\section{Analysis of correlation between AD biomarker in CSF and contact factor activity in plasma}

To examine further the strength of a link between the typical CSF AD biomarkers and the contact factors, we performed correlation analyses (Fig. 1i - 1; Supplementary Table 1). As for the typical CSF AD biomarkers, the Pearson's correlation coefficients of $A \beta_{1-42}$ versus $t-T a u$ and $\mathrm{p}-\mathrm{Tau}_{181}$ were to be -0.445 and -0.359 , respectively, 
Table 2 Overview of precision and reproducibility

\begin{tabular}{|c|c|c|c|c|c|c|c|c|}
\hline \multirow[t]{2}{*}{ Biomarker } & \multirow[t]{2}{*}{ Sample } & \multirow{2}{*}{$\begin{array}{l}\mathrm{U} / \\
\mathrm{ml}\end{array}$} & \multicolumn{3}{|c|}{ Intra-assay variation $(n=6)$} & \multicolumn{3}{|c|}{ Inter-assay variation $(n=4)$} \\
\hline & & & Mean & SD & CV (\%) & Mean & SD & CV (\%) \\
\hline \multirow[t]{3}{*}{ FXlla } & Sample 1 & 0.5 & 0.441 & 0.020 & 4.5 & 0.482 & 0.061 & 12.7 \\
\hline & Sample 2 & 1.5 & 1.458 & 0.047 & 3.2 & 1.521 & 0.165 & 10.9 \\
\hline & Sample 3 & 2.5 & 2.469 & 0.091 & 3.7 & 2.668 & 0.193 & 7.2 \\
\hline \multirow[t]{3}{*}{ FXla } & Sample 1 & 0.05 & 0.058 & 0.002 & 2.6 & 0.053 & 0.006 & 11.7 \\
\hline & Sample 2 & 0.1 & 0.095 & 0.004 & 4.2 & 0.100 & 0.010 & 10.1 \\
\hline & Sample 3 & 0.2 & 0.199 & 0.008 & 4.1 & 0.197 & 0.019 & 9.4 \\
\hline \multirow[t]{3}{*}{ FXa } & Sample 1 & 0.1 & 0.103 & 0.010 & 9.4 & 0.103 & 0.010 & 10.2 \\
\hline & Sample 2 & 0.2 & 0.200 & 0.011 & 5.5 & 0.196 & 0.017 & 8.9 \\
\hline & Sample 3 & 0.5 & 0.510 & 0.023 & 4.5 & 0.515 & 0.059 & 11.5 \\
\hline \multirow[t]{3}{*}{ Plasma kallikrein } & Sample 1 & 0.1 & 0.125 & 0.004 & 3.0 & 0.110 & 0.012 & 11.3 \\
\hline & Sample 2 & 0.2 & 0.191 & 0.013 & 6.9 & 0.190 & 0.017 & 8.8 \\
\hline & Sample 3 & 0.4 & 0.418 & 0.037 & 8.8 & 0.421 & 0.049 & 11.8 \\
\hline
\end{tabular}

Both intra ( $n=6$ replicates) and inter-assay ( $n=4$ assays on different day) precision were determined by comparing the mean of triplicates of three deferent concentrations of samples. The \% CV is the standard deviation divided by the mean and multiplied by 100 . Abbreviations: SD standard deviation, CV coefficients of variation, FXIla active coagulation factor XII, FXla active coagulation factor XI, FXa active coagulation factor X
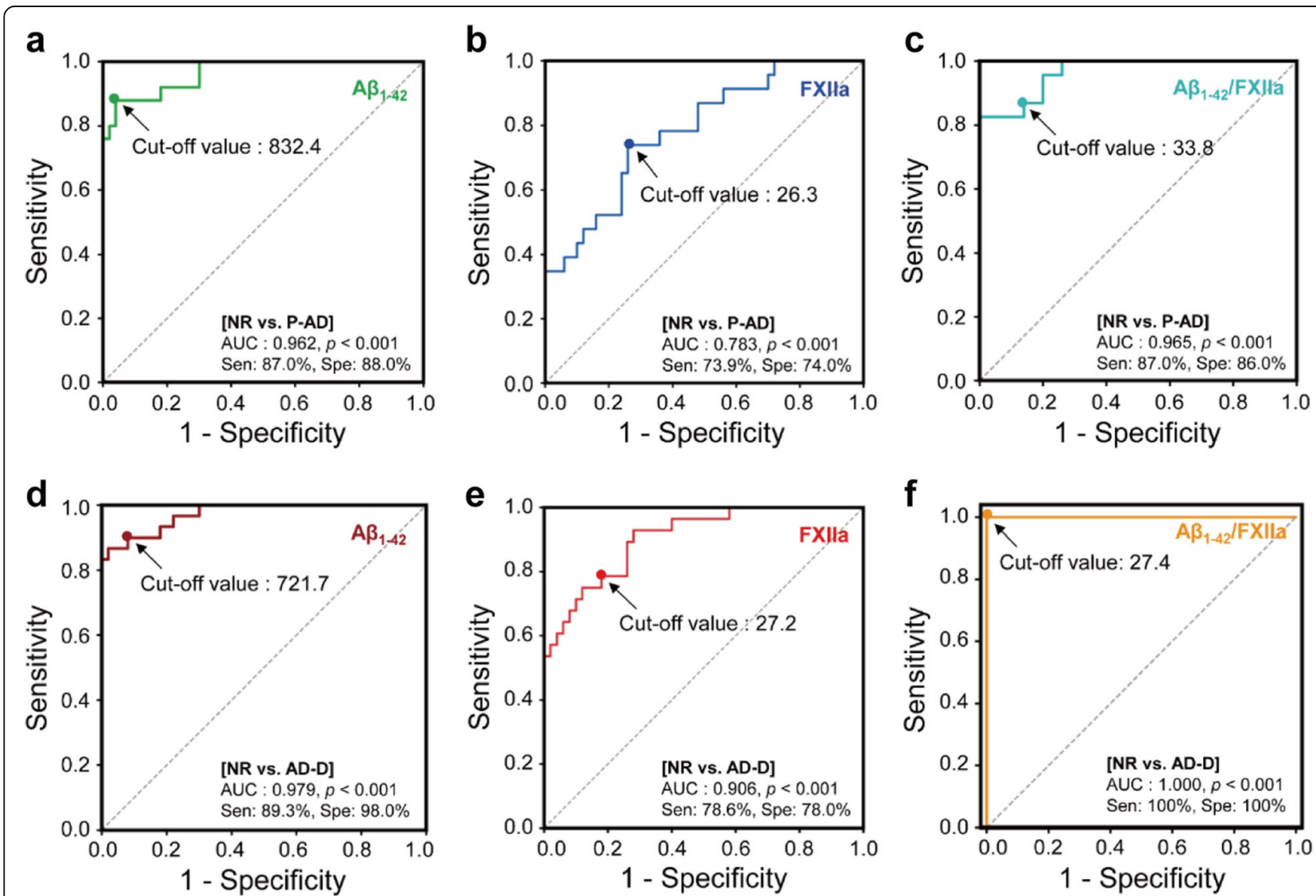

Fig. 2 Representative cut-off values of contact factors and CSF $A \beta_{1-42} /$ contact factor ratios. Cut-off values of $A \beta_{1-42}(\mathbf{a}), F X I l a(\mathbf{b})$, and CSF $A \beta_{1-42} /$ FXIla ratio $(\mathbf{c})$ capable of discriminating prodromal AD from normal. Cut-off values of $A \beta_{1-42}(\mathbf{d}), F X I l a(\mathbf{e})$, and CSF $A \beta_{1-42} / F X I l a$ ratio (f). ROC curves are shown for each marker, in which arrows indicate cut-off values capable of distinguishing P-AD and AD-D groups from NR 
at their $r$-values, indicating that these biomarkers are moderately correlated, under the guidelines of correlation strength [29]. In cases of contact factors, the $r$-values of FXIIa versus FXIa, FXa, and PK were to be 0.8, 0.692, and 0.59 , respectively, suggesting that these factors are correlated statistically in significant level (Supplementary Table 1). Prominently, FXIIa was negatively correlated to CSF $\mathrm{A} \beta_{1-42}(r=-0.463)$ and positively to both $\mathrm{t}-\mathrm{Tau}(r=$ $0.509)$ and $\mathrm{p}-\mathrm{Tau}_{181}(r=0.452)$ in all moderate relationships (Fig. 1i - 1; Supplementary Table 1). All these results suggest that the activation of contact system is certainly correlated to AD progression as reported previously [17].

The changes in the $z$-values of typical CSF AD biomarkers and plasma contact factors as AD progresses were also analyzed (Fig. 1m). As expected [5, 12, 16, 30], the $z$-score of $A \beta_{1-42}$ decreased, whereas those of $\mathrm{t}$-Tau and $\mathrm{p}-\mathrm{Tau}_{181}$ increased in the order of normal, prodromal AD, and AD dementia groups (Fig. 1m). As for plasma contact factors, the scores of FXIIa, FXIa, FXa, and PK noticeably increased (Fig. 1m), whereas CSF BK decreased (data not shown) in the AD pathological cascade. These results strongly suggest that plasma contact system is closely associated with AD progression, and its degree of activation can reflect the disease progression.

\section{Analysis of potential as a plasma biomarker for AD diagnosis}

We generated receiver operating characteristic (ROC) curves to analyze the potential of each protein for use as a new biomarker for $\mathrm{AD}$ diagnosis (Fig. 2 and Table 3). The ROC curves and the areas under the curves (AUCs) $[28,31]$ showed that $A \beta_{1-42}$ can discriminable in highly accurate for both prodromal AD (AUC $=0.962$; cut-off value $=<832.4 \mathrm{pg} / \mathrm{ml})$ and $\mathrm{AD}$ dementia $(\mathrm{AUC}=0.979$; cut-off value $=<721.7 \mathrm{pg} / \mathrm{ml}$ ) from normal (Fig. $2 \mathrm{a}$, d; Table 3). Among the contact factors, only FXIIa seemed to have a capability able to discriminate both prodromal $\mathrm{AD}(\mathrm{AUC}=0.783$; cut-off value $=>26.3 \mathrm{U} / \mathrm{ml})$ and $\mathrm{AD}$ dementia $($ AUC $=0.906$; cut-off value $=>27.2 \mathrm{U} / \mathrm{ml}$ ) from normal (Fig. 2b,e; Table 3). These results indicate that the contact factor FXIIa can be a new plasma biomarker for diagnosing prodromal $\mathrm{AD}$ in acceptable and $\mathrm{AD}$ dementia in very accurate from normal.

In particular, the CSF $A \beta_{1-42} / F X I I a$ ratio showed very accurate for prodromal AD (AUC $=0.965$; cut-off value $=<33.8$ ) and perfect diagnostic abilities for AD dementia $(\mathrm{AUC}=1.0$; cut-off value $=<27.44)$ (Fig. $2 \mathrm{c}$, f; Table 3). Taken together, these results suggest that, 1) FXIIa can be used as a plasma biomarker for early diagnosis of prodromal $A D$, and 2) use of the $A \beta_{1-42} /$ FXIIa ratio improves diagnostic accuracy.

\section{Conclusions}

Based on the results, we conclude that 1) activation of plasma contact system is not only correlated with $\mathrm{AD}$ progression, but also is available for AD diagnosis; 2) the degree of $\mathrm{AD}$ progress can be quickly determined by measuring the activities of contact factors in blood

Table 3 Cut-off scores and sensitivity/specificity values of fluid biomarkers for discriminating the prodromal AD or AD dementia from normal subjects

\begin{tabular}{|c|c|c|c|c|c|c|c|c|c|c|}
\hline \multirow[t]{2}{*}{ Characteristics } & \multicolumn{5}{|c|}{ Normal $(n=50)$ vs. Prodromal AD $(n=23)$ groups } & \multicolumn{5}{|c|}{ Normal $(n=50)$ vs. AD dementia $(n=28)$ groups } \\
\hline & Cut-off & Sen $(\%)$ & Spe (\%) & AUC & $p$ value & Cut-off & Sen (\%) & Spe (\%) & AUC & $p$ value \\
\hline \multicolumn{11}{|l|}{ Plasma factors } \\
\hline FXlla activity, U/ml & $>26.3$ & 73.9 & 74.0 & 0.783 & $<0.001$ & $>27.2$ & 78.6 & 78.0 & 0.906 & $<0.001$ \\
\hline FXla activity, $\mathrm{U} / \mathrm{ml}$ & $>1.13$ & 52.2 & 52.0 & 0.566 & 0.367 & $>1.17$ & 57.1 & 58.0 & 0.659 & 0.020 \\
\hline FXa activity, $\mathrm{U} / \mathrm{ml}$ & $>0.76$ & 56.5 & 54.0 & 0.573 & 0.316 & $>0.82$ & 71.4 & 70.0 & 0.779 & $<0.001$ \\
\hline Kallikrein activity, $\mathrm{U} / \mathrm{ml}$ & $>1.21$ & 56.5 & 56.0 & 0.609 & 0.138 & $>1.29$ & 64.3 & 64.0 & 0.772 & $<0.001$ \\
\hline \multicolumn{11}{|l|}{ CSF biomarkers } \\
\hline $\mathrm{A} \beta_{1-42}$ levels, $\mathrm{pg} / \mathrm{ml}$ & $<832.4$ & 87.0 & 88.0 & 0.962 & $<0.001$ & $<721.7$ & 89.3 & 98.0 & 0.979 & $<0.001$ \\
\hline t-Tau levels, pg/ml & $>252.6$ & 65.2 & 66.0 & 0.701 & 0.006 & $>315.3$ & 85.7 & 86.0 & 0.954 & $<0.001$ \\
\hline p-Tau 181 levels, pg/ml & $>46.1$ & 65.2 & 64.0 & 0.690 & 0.009 & $>46.1$ & 78.6 & 78.0 & 0.870 & $<0.001$ \\
\hline BK levels, pg/ml & $>46.1$ & 54.5 & 56.5 & 0.656 & 0.073 & $>52.8$ & 74.1 & 73.9 & 0.783 & 0.001 \\
\hline \multicolumn{11}{|l|}{ Ratios } \\
\hline$A \beta_{1-42} /$ FXIla & $<33.8$ & 87.0 & 86.0 & 0.965 & $<0.001$ & $<27.4$ & 100.0 & 100.0 & 1.000 & $<0.001$ \\
\hline$A \beta_{1-42} / F X l a$ & $<742.5$ & 82.6 & 82.0 & 0.930 & $<0.001$ & $<635.4$ & 96.4 & 96.0 & 0.993 & $<0.001$ \\
\hline$A \beta_{1-42} / F X a$ & $<1,091$ & 82.6 & 82.0 & 0.933 & $<0.001$ & $<941.8$ & 96.4 & 96.0 & 0.994 & $<0.001$ \\
\hline$A \beta_{1-42} /$ Kallikrein & $<680.9$ & 87.0 & 86.0 & 0.943 & $<0.001$ & $<584.8$ & 96.4 & 96.0 & 0.994 & $<0.001$ \\
\hline
\end{tabular}

Statistically-derived optimal cut-off value was determined with the best balance between sensitivity (Sen) and specificity (Spe) values. Discrimination of prodromal $A D$ and $A D$ dementia from normal group was evaluated by receiver operator characteristics (ROC) curve analysis and quantified by the area under the curve (AUC) using SPSS software version 24.0 
plasma; 3) among the contact factors, FXIIa can be used as a new plasma biomarker for diagnosing prodromal $\mathrm{AD}$ and $\mathrm{AD}$ dementia at early stage, and 4) the use of $\mathrm{A} \beta_{1-42} /$ FXIIa ratio improves diagnostic accuracy for discriminating prodromal $\mathrm{AD}$ and $\mathrm{AD}$ dementia from normal.

\section{Supplementary Information}

The online version contains supplementary material available at https://doi. org/10.1186/s40364-020-00258-5.

Additional file 1: Supplementary Figure 1. The standard curves for contact factors activities (FXIla, FXla, Fxa, and plasma kallikrein). The curves were fitted by sigmoidal 4 parameter curve of data points.

Additional file 2:: Supplementary Table 1. Correlation of CSF AD biomarkers and plasma contact factors.

\section{Abbreviations}

AD: Alzheimer's disease; FXlla: Factor XIla; AB: Amyloid-beta; FXI: Factor Xl; PKK: Prekallikrein; HK: High-molecular weight kininogen; PK: Plasma kallikrein; BK: Bradykinin; CSF: Cerebrospinal fluid; BBB: Blood-brain barrier

\section{Acknowledgments}

The authors thank the study participants and the Gwangju Alzheimer's disease and related Dementias cohort center (Chosun University, Gwangju, Republic of Korea) for provide all the clinical data.

\section{Authors' contributions}

JEP conducted the study, analyzed the data, and wrote the manuscript; DSL and $\mathrm{YHC}$ performed the research; KYC and JJ analyzed the data; KHL provided clinical information; BCK diagnosed study participants; and JSL designed the study, analyzed the data, and wrote the manuscript. All authors read and approved the final manuscript.

\section{Funding}

This research was supported by the Brain Research Program through the National Research Foundation of Korea (NRF) funded by the Ministry of Science, ICT and Future Planning (2016M3C7A1905469). This study was also supported in part by a research fund from Chosun University, 2015.

\section{Availability of data and materials}

For original data, please contact jsplee@chosun.ac.kr. Detailed data on correlation and cut-off scores may be found in "Supplemental Table 1" available with the online version of this article.

\section{Ethics approval and consent to participate}

All participants in this study provided their written consents, and the study protocol was approved by Chosun University Hospital Institutional Review Board.

\section{Consent for publication}

Not applicable.

\section{Competing interests}

The authors have declared that no conflict of interest.

\section{Author details}

${ }^{1}$ Department of Biomedical Science, College of Natural Sciences, Chosun University, 309 Pilmun-Daero, Gwangju 61452, Republic of Korea. ${ }^{2}$ Department of Integrative Biological Sciences \& BK21-Four Educational Research Group for Age-associated Disorder Control Technology, Chosun University, Gwangju, Republic of Korea. ${ }^{3}$ Gwangju Alzheimer's disease and related Dementias Cohort Center, Chosun University, Gwangju, Republic of Korea. ${ }^{4}$ Department of Neurology, Chonnam National University Medical School, Gwangju, Republic of Korea.
Received: 17 September 2020 Accepted: 21 December 2020

Published online: 09 January 2021

\section{References}

1. Bronzuoli MR, lacomino A, Steardo L, Scuderi C. Targeting neuroinflammation in Alzheimer's disease. J Inflamm Res. 2016;9:199-208.

2. Blennow K. A review of fluid biomarkers for Alzheimer's disease: Moving from CSF to blood. Neurol Ther. 2017;6(Suppl 1):15-24.

3. Thambisetty M, Lovestone S. Blood-based biomarkers of Alzheimer's disease: challenging but feasible. Biomark Med. 2010;4(1):65-79.

4. O'Bryant SE, Mielke MM, Rissman RA, Lista S, Vanderstichele $\mathrm{H}$, Zetterberg $\mathrm{H}_{\text {, }}$ et al. Blood-based biomarkers in Alzheimer disease: current state of the science and a novel collaborative paradigm for advancing from discovery to clinic. Alzheimers Dement. 2017;13(1):45-58

5. Jack CR Jr, Knopman DS, Jagust WJ, Petersen RC, Weiner MW, Aisen PS, et al. Tracking pathophysiological processes in Alzheimer's disease: an updated hypothetical model of dynamic biomarkers. Lancet Neurol. 2013; 12(2):207-16.

6. Sperling RA, Aisen PS, Beckett LA, Bennett DA, Craft S, Fagan AM, et al. Toward defining the preclinical stages of Alzheimer's disease: recommendations from the National Institute on Aging-Alzheimer's Association workgroups on diagnostic guidelines for Alzheimer's disease. Alzheimers Dement. 2011;7(3):280-92

7. Anoop A, Singh PK, Jacob RS, Maji SK. CSF biomarkers for Alzheimer's disease diagnosis. Int J Alzheimers Dis. 2010;2010:606802.

8. Mari D, Parnetti L, Coppola R, Bottasso B, Reboldi GP, Senin U, et al. Hemostasis abnormalities in patients with vascular dementia and Alzheimer's disease. Thromb Haemost. 1996;75(2):216-8.

9. Gupta A, Watkins A, Thomas P, Majer R, Habubi N, Morris G, et al. Coagulation and inflammatory markers in Alzheimer's and vascular dementia. Int J Clin Pract. 2005:59(1):52-7.

10. Heneka MT, Carson MJ, El Khoury J, Landreth GE, Brosseron F, Feinstein DL et al. Neuroinflammation in Alzheimer's disease. Lancet Neurol. 2015;14(4): 388-405.

11. Zamolodchikov D, Chen ZL, Conti BA, Renne T, Strickland S. Activation of the factor XII-driven contact system in Alzheimer's disease patient and mouse model plasma. Proc Natl Acad Sci U S A. 2015:112(13):4068-73.

12. Chen ZL, Revenko AS, Singh P, MacLeod AR, Norris EH, Strickland S. Depletion of coagulation factor XII ameliorates brain pathology and cognitive impairment in Alzheimer disease mice. Blood. 2017;129(18):2547-56.

13. Park JE, Park JW, Lee W, Lee JS. Pleiotropic effects of a vibrio extracellular protease on the activation of contact system. Biochem Bioph Res Co. 2014; 450(2):1099-103.

14. Wu Y. Contact pathway of coagulation and inflammation. Thromb J. 2015 $13: 17$

15. Maas C, Govers-Riemslag JW, Bouma B, Schiks B, Hazenberg BP, Lokhorst $\mathrm{HM}$, et al. Misfolded proteins activate factor XII in humans, leading to kallikrein formation without initiating coagulation. J Clin Invest. 2008;118(9): 3208-18.

16. Merlini M, Akassoglou K. Alzheimer disease makes new blood contacts. Blood. 2017:129(18):2462-3.

17. Yamamoto-Imoto H, Zamolodchikov D, Chen Z-L, Bourne SL, Rizvi S, Singh $P$, et al. A novel detection method of cleaved plasma high-molecularweight kininogen reveals its correlation with Alzheimer's pathology and cognitive impairment. Alzheimers Dement. 2018;10:480-9.

18. Singh PK, Chen Z-L, Strickland S, Norris EH. Increased Contact System Activation in Mild Cognitive Impairment Patients with Impaired Short-Term Memory. J Alzheimers Dis. 2020;77(1):59-65.

19. Chen Z-L, Singh P, Wong J, Horn K, Strickland S, Norris EH. An antibody against HK blocks Alzheimer's disease peptide $\beta$-amyloid- induced bradykinin release in human plasma. Proc Natl Acad Sci. 2019;116(46): 22921-3.

20. Dubois B, Feldman HH, Jacova C, Hampel H, Molinuevo JL, Blennow K, et al Advancing research diagnostic criteria for Alzheimer's disease: the IWG-2 criteria. Lancet Neurol. 2014;13(6):614-29.

21. Cummings JL, Khachaturian ZS. Definitions and diagnostic criteria. In: Clinical diagnosis and management of Alzheimer's disease, vol. 3; 2007.

22. Lim HJ, Park JE, Kim BC, Choi S-M, Song M-K, Cho SH, et al. Comparison of Two Analytical Platforms in Cerebrospinal Fluid Biomarkers for the Classification of Alzheimer's Disease Spectrum with Amyloid PET Imaging. J Alzheimers Dis. 2020;75(3):949-58. 
23. Guerin JS, Murray DW, McGrath MM, Yuille MA, McPartlin JM, Doran PP. Molecular medicine Ireland guidelines for standardized biobanking. Biopreserv Biobank. 2010;8(1):3-63.

24. Slemmon JR, Meredith J, Guss V, Andreasson U, Andreasen N, Zetterberg H, et al. Measurement of $A \beta 1-42$ in cerebrospinal fluid is influenced by matrix effects. J Neurochem. 2012;120(2):325-33.

25. Parnetti L, Chiasserini D, Eusebi P, Giannandrea D, Bellomo G, De Carlo C, et al. Performance of abeta1-40, abeta1-42, total tau, and phosphorylated tau as predictors of dementia in a cohort of patients with mild cognitive impairment. J Alzheimers Dis. 2012;29(1):229-38.

26. Wu J, Akaike T, Hayashida K, Miyamoto Y, Nakagawa T, Miyakawa K, et al, Identification of bradykinin receptors in clinical cancer specimens and murine tumor tissues. Int J Cancer. 2002;98(1):29-35.

27. Singh PK, Chen Z-L, Ghosh D, Strickland S, Norris EH. Increased plasma bradykinin level is associated with cognitive impairment in Alzheimer's patients. Neurobiol Dis. 2020;139:104833.

28. Marcos-Contreras OA, Martinez de Lizarrondo S, Bardou I, Orset C, Pruvost M, Anfray A, et al. Hyperfibrinolysis increases blood-brain barrier permeability by a plasmin- and bradykinin-dependent mechanism. Blood. 2016;128(20):2423-34.

29. Mukaka MM. Statistics corner: A guide to appropriate use of correlation coefficient in medical research. Malawi Med J. 2012;24(3):69-71.

30. Hu WT, Watts KD, Shaw LM, Howell JC, Trojanowski JQ, Basra S, et al. CSF beta-amyloid 1-42 - what are we measuring in Alzheimer's disease? Ann Clin Transl Neur. 2015;2(2):131-9.

31. Greiner M, Pfeiffer D, Smith RD. Principles and practical application of the receiver-operating characteristic analysis for diagnostic tests. Prev Vet Med. 2000;45(1-2):23-41.

\section{Publisher's Note}

Springer Nature remains neutral with regard to jurisdictional claims in published maps and institutional affiliations.

Ready to submit your research? Choose BMC and benefit from:

- fast, convenient online submission

- thorough peer review by experienced researchers in your field

- rapid publication on acceptance

- support for research data, including large and complex data types

- gold Open Access which fosters wider collaboration and increased citations

- maximum visibility for your research: over $100 \mathrm{M}$ website views per year

At $\mathrm{BMC}$, research is always in progress.

Learn more biomedcentral.com/submissions 